\title{
DA SAÚDE À DOENÇA: REPRESENTAÇÕES SOCIAIS SOBRE A INSUFICIÊNCIA RENAL CRÔNICA E 0 TRANSPLANTE RENAL
}

\author{
From Sickness To Health: Social Representations About Chronic \\ Renal Insufficiency And Kidney Transplantation.
}

Alberto Manuel Quintana ${ }^{1}$

Ana Cláudia Müller²

\section{Resumo}

A insuficiência renal crônica (IRC) é uma enfermidade que provoca a penda parcial ou total da função glomerular. O transplante é uma das modalidades de tratamento renal substitutivo que visa a oferecer melhor qualidade de vida e bem-estar aos pacientes portadores de IRC. Além das alterações orgânicas, essa doença também pode causar disfunções psíquicas e sociais. Este artigo é relato de uma pesquisa que objetivou explorar quais as representações sociais construídas por estes sujeitos acerca de sua enfermidade e do transplante renal. Para isso, utilizou-se dos recursos de observação participante e entrevista semi-estruturada nos ambulatórios de pré e pós-transplante do Hospital Universitário de Santa Maria, instituição referência na realização de transplantes renais na região central do estado do Rio Grande do Sul. Pela análise dos dados, pôde-se perceber que a doença crônica é vivenciada como um momento de ruptura na vida dos pacientes, a noção temporal deles é delimitada pelo antes e depois do diagnóstico. Além disso, o transplante é significado como uma forma idealizada de cura, mas que é desmistificada após a cirurgia.

Palavras-chave: Psicologia médica, Transplante renal, Insuficiência renal crônica.

Doutor em Ciências Sociais (Antropologia). Mestre em Psicologia Clínica. Professor do Departamento de Psicologia da UFSM

2 Psicóloga

Endereço para correspondência: Rua Dr. Bozano, 103 ap. 103. Santa Maria - RS. 97015-001.

E-mail: anaclaudiamuller@bol.com.br 
Abstract

The Chronic Renal Insufficiency (CRI) is a disease that provokes the total or partial loss of the glomerular function. The transplant is one of the types of renal substitutive treatment that aims to offer better quality of life and well-being to patients who are CRI carriers. Besides organic alterations, this disease may also cause psychological and social dysfunctions. This article reports a research that targeted to explore which social representations are built by the subjects about their disease and kidney transplantation. The resources used were participant observation and semi-structured interviews in the pre and post transplant outpatient treatment taking place in Hospital Universitário de Santa Maria, which is a reference institution conceming the accomplishment of kidney transplants in the central region of Rio Grande do Sul. Through the analysis of the data gathered it was possible to perceive that this chronic disease is lived as a moment of rupture in the patients' lives, their concept of time is delimited by their life experience before and after the diagnosis. Moreover, the transplant has the meaning of an idealized form of cure, though it is understood differently after surgery.

Keywords: Psychology medical, Kidney transplant, Kidney failure chronic.

\section{Introdução}

A medicina tem apresentado um surpreendente desenvolvimento, nas últimas décadas, ocasionado pela criação de novas técnicas de tratamento e pela alta sofisticação diagnóstica. Esse notável progresso resultou na melhora da qualidade de vida daqueles que sofrem de uma enfermidade e também no prolongamento da longevidade deles.

Apesar dessa revolução tecnológica da medicina, o adoecer continua sendo um processo doloroso para aqueles que sofrem de alguma patologia. A enfermidade orgânica vem acompanhada de algumas reações emocionais, tais como ansiedade, tristeza, depressão, dor, medos e até, em alguns casos, da iminência da morte. Para lidar com esta dimensão existencial que se potencializa no adoecimento, uma área de atuação psicológica denominada Psicologia Hospitalar vem ganhando força e cada vez mais espaço no Brasil (CRP-SP, 2003). Dentro desta área de intervenção, uma em particular tem merecido especial atenção dos psicólogos inseridos em instituições hospitalares: a Psiconefrologia.

A insuficiência renal crônica corresponde a uma síndrome caracterizada pela perda progressiva e irreversível da função renal. Ela exige renúncias do seu portador, bem como adaptação de sua vida a uma nova situação: a de doente. Nesse espaço é que se insere a Psiconefrologia, intervindo junto a pacientes freqüentadores de ambulatórios e hospitalizados, visando a minimizar o impacto causado pela doença e auxiliar na aderência ao tratamento, assim como acompanhando a família do enfermo nesse período crítico (Diniz, Filho \& Lima, 2002).
A maioria das publicações relacionada à Psiconefrologia é encontrada em periódicos internacionais e tem focado aspectos quantitativos relacionados a índices de depressão e qualidade de vida dos pacientes em diferentes modalidades de tratamento (Finkelstein \& Finkelstein, 2000; Huh, Kim \& Lee, 2002; Vergoulas, 2002). Já os aspectos qualitativos da patologia em questão são pouco abordados, embora exista um interesse incipiente tanto da psicologia quanto de outras áreas afins (Borges, 1998; Lima, 2000). Objetivando suprir essa lacuna, interessou-nos realizar um estudo qualitativo visando a conhecer como os pacientes renais crônicos representam a sua enfermidade e o transplante renal.

\section{O Transplante Renal: Aspectos Clíni- cos e Psicológicos}

Para se compreender o transplante renal é necessário conhecer o caminho que os pacientes percorrem até realizar tal procedimento. De acordo com Barros, Gonçalves, Manfro e Thomé (1994), até que tenham perdido cerca de $50 \%$ de sua função renal, os sujeitos conservam-se sem sintomas. Ultrapassado esse limiar, os rins já não conseguem exercer suas funções adequadamente e os pacientes necessitam de um acompanhamento ambulatorial. Submetem-se, então, ao tratamento conservador que consiste no controle da doença básica, da hipertensão arterial, da dieta alimentar e de possíveis agravantes da perda de função glomerular. Quando esta modalidade terapêutica já não resulta em boa qualidade de vida, é recomendado o tratamento renal substitutivo - diálise peri- 
toneal, hemodiálise ou transplante - assim denominado por exercer as funções correspondentes aos rins.

Como para o transplante renal são necessárias avaliações clínicas, preparação cirúrgica e/ ou espera em lista, muitos pacientes iniciam hemodiálise ou diálise peritoneal antes de estarem aptos para esta intervenção cirúrgica. A hemodiálise consiste na filtração do sangue pelo bombeamento deste para dentro de uma máquina na qual há um dialisador - uma espécie de membrana artificial - que possui uma solução responsável pela retirada das substâncias tóxicas e do excesso de líquido do organismo. Depois desse processo, o sangue limpo retorna ao organismo pela fístula arterio-venosa. Já para a diálise peritoneal, o paciente necessita realizar um procedimento cirúrgico para introdução de um cateter na região abdominal. Por esse cateter, ocorre a eliminação de substâncias tóxicas do organismo pela permuta entre 0 sangue e uma solução dialisadora realizada por meio de uma membrana semipermeável natural: 0 peritônio (Maciel, 2002).

Conforme os autores mencionados acima, o transplante renal pode ser realizado com doador cadáver, vivo relacionado ou não-relacionado. A adequação entre doador e receptor depende da compatibilidade anatômica do órgão, da tipagem sangüínea e, principalmente, da semelhança de HLA - obtida por prova cruzada, teste de microlinfotoxicidade que visa a detectar anticorpos citotóxicos contra o antígeno HLA do doador presentes no soro do receptor. No caso de um paciente em lista, o tempo de espera por um rim determina o seu recebimento ou não, além do estado clínico no momento do transplante (Barros et al., 1994).

Esta escolha relaciona-se à compatibilidade clínica, mas também à disponibilidade afetiva de um familiar para tal cirurgia (Uryn, 1992). O início do processo de seleção de um possível doador vivo mobiliza vários membros da família do paciente renal crônico e desperta nestes sentimentos ambíguos quanto à doação. O doador vivo sofre com o medo da morte, de não acordar da anestesia, de ficar com cicatrizes, de não suportar a dor ou de ficar com o corpo deformado. Por outro lado, o receptor teme a possibilidade fantasiosa de adquirir características físicas e comportamentais de seu doador ou de que este venha a ter problemas devido à falta do rim doado. Já o paci- ente à espera de um enxerto cadáver pode sentirse culpado pelo fato de depender da morte de uma pessoa para conseguir um rim (Júnior \& Zimmermann, 2002).

O transplante renal está associado à diminuição na prevalência de transtornos mentais, em especial dos níveis de depressão em paciente renais crônicos. No entanto, esta melhora pode demorar um período de alguns meses para ser observada, pois a fase pós-cirúrgica requer a readaptação do indivíduo a sua nova condição de saúde e o enfrentamento de outras ansiedades. $\mathrm{O}$ transplantado necessita enfrentar o medo da perda do órgão enxertado; o receio de se afastar da equipe médica; a insegurança quanto à capacidade de seguir em casa todas as orientações dadas; as preocupações em retornar a seus papéis na família, no trabalho e na sociedade (Almeida, 2003; Júnior \& Zimmermann, 2002).

No entanto, alguns pacientes sofrem a rejeição do enxerto transplantado. Estes se deparam com uma situação especial, onde sonhos e expectativas idealizadas de cura da doença são desconstruídos. A rejeição do rim enxertado é seguida de tristeza e decepção, podendo o paciente apresentar comportamentos incriminatórios em relação à equipe de saúde e aos seus familiares, acusando-os de negligência e descuido (Uryn, 1992).

\section{A Imagem Corporal e o Transplante}

Cada indivíduo cria para si uma imagem corporal a partir da interação de aspectos sociais, libidinais e fisiológicos. De acordo com Rodrigues (1979), o corpo e seus comportamentos são historicamente determinados e reconstruídos ao longo do tempo a partir de valores, códigos e símbolos preponderantes na cultura:

Se considerarmos todas as modelações que sofre, constataremos que o corpo é pouco mais que uma massa de modelagem à qual a sociedade imprime formas segundo suas próprias disposições (...) Arranhando, rasgando, perfurando, queimando a pele - imprime-se cicatrizes-signos que são formas artísticas ou indicadores rituais de status (p. 62).

O adoecimento é um rompimento dessa 
imagem e exige uma mobilização simbólica para ressignificá-la. A doença surge como algo não-familiar e o indivíduo necessita atribuir um sentido ao porquê do mal biológico, assim como às circunstâncias que possibilitaram que ela emergisse. Para isso, constrói representações sociais acerca da doença e suas terapêuticas (Duarte, 1986; Loyola, 1984; Montero, 1985; Quintana, 1999).

As representações sociais são um sistema de teorias populares, senso comum e saberes cotidianos/práticos utilizados pelos sujeitos para dar significado a si e ao ambiente que o cerca:

O sujeito constrói, na sua relação com o mundo, um novo mundo de significados. De um lado, é através de sua atividade e relação com outros que as representações têm origem, permitindo uma mediação entre 0 sujeito e 0 mundo que ele ao mesmo tempo descobre e constrói. De outro lado, as representações permitem a existência de símbolos - pedaços de realidade social para dar sentido e forma às circunstâncias nas quais eles se encontram (Jovchelovitch, 1995, p. 78).

O desconhecido que surge a partir de pontos de tensão no universo simbólico de uma sociedade, bem como o medo decorrente de uma ruptura nesse universo levam as pessoas a criarem representações sociais de novos fenômenos, pois coisas desconhecidas ameaçam o sentido de ordem e a sensação de controle do sujeito sobre si mesmo e sobre o mundo (Berger \& Luckmann, 1976; Moscovici, 2003).

As representações sociais dos pacientes renais - que estão na expectativa de receber um rim ou que já realizaram o transplante - resultam de um esforço constante em tornar algo que traz uma sensação de não-familiaridade em algo comum e real.

\section{Metodologia}

Para explorar as representações construídas pelos portadores de insuficiência renal crônica - em fase de avaliação pré-transplante ou já transplantados - acerca do transplante renal e da doença, utilizou-se a pesquisa qualitativa, tendo em vista que esta se adequava melhor à proposta do trabalho. Durante o processo de coleta de dados, foram realizadas entrevistas semi-estruturadas e observações participantes nos ambulatórios de pré e pós-transplante renal do Hospital Universitário de Santa Maria, instituição referência neste procedimento na região central do Rio Grande do Sul.

A técnica de observação participante estabelece-se a partir do contato direto do pesquisador com o fenômeno observado, obtendo-se informações acerca da realidade dos atores sociais em seus próprios contextos (Minayo, 2002). As observações foram realizadas ao longo de três meses, período este que permitiu a familiarização com a realidade dos pacientes e a aquisição de mais subsídios para a realização das entrevistas.

As entrevistas semi-estruturadas foram usadas como forma de buscar informações acerca do tema estudado a partir da fala dos atores sociais e de explorar a trajetória da doença desde 0 momento do diagnóstico até o tratamento (Minayo, 2002). No total, foram entrevistados sete pacientes, sendo que, destes, quatro eram freqüentadores do ambulatório do pré-transplante e três pacientes transplantados. $\mathrm{O}$ número de sujeitos utilizado na pesquisa foi determinado a partir do critério de saturação proposto por Moraes (2003): “Entende-se que a saturação é a tingida quando a introdução de novas informações nos produtos da análise já não produz modificações nos resultados anteriormente atingidos" (p. 199).

Optou-se, na análise dos dados, por utilizar a análise de conteúdo proposta por Bardin (1988), a qual visa a descoberta do que está atrás dos conteúdos manifestos, indo além das aparências do que está sendo comunicado. Dessa forma, pelos procedimentos sistemáticos, buscou-se relacionar estruturas semânticas (significantes) com estruturas sociológicas e psicológicas (significados) dos enunciados produzidos pelos indivíduos (Bardin, 1988; Minayo, 2002).

\section{Representações Sociais da Doença e do Transplante Renal}

Partindo do referencial da análise de conteúdo, as falas dos entrevistados foram enquadradas em categorias temáticas que abrangessem idéias com características comuns. As classificações temáticas mais significativas encontradas ao longo da análise dos dados serão apresentadas a seguir e ilustradas com recortes das entrevistas. A doença não é vista pelos pacientes como dissociada de 
suas terapêuticas, por isso também há categorias e passagens referentes às modalidades de tratamento distintas do transplante.

\section{0 impacto do diagnóstico}

Receber o diagnóstico de uma doença renal crônica é um momento ansiogênico, visto que esta é associada pelos pacientes a um mau prognóstico e à iminência da morte (Penna, 1992). Na fala dos entrevistados, evidenciou-se que o diagnóstico é vivenciado como a confirmação da perda por todo o controle sobre a vida. Esta sensação de desamparo e impotência tenta ser revertida pela retomada do controle se não sobre a sua vida, pelo menos sobre a sua morte:

"O Dr. me disse: Tu tem problema renal, vai ter que fazer a hemodiálise'. 'De jeito nenhum, hemodiálise eu não faço, nem que eu me atire daqui, eu não faço'. Na hora me deu aquele choque, né! (...) Eu pensei 'hemodiálise, puxa vida, eu vou morrer. Então eu morro antes'. Quando me disseram que eu ia fazer hemodiálise eu achei que ia morrer" (E4, aposentado, pré-transplante).

A fala desse paciente exemplifica a reação psíquica mencionada por Diniz et al. (2002) diante da notícia de uma doença crônica:

Quando o diagnóstico é realizado e posta a situação de cronicidade (segundo momento), a reação geral é um sentimento de caos, de impotência. A família sente-se confusa, conturbada. Um terceiro momento surge. Esse marcado por reações de defesa até mesmo de negação no que concerne à gravidade da doença e à sua irreversibilidade. Enfim, quando a invalidez, seja ela mínima ou grave, é admitida, pode sobrevir uma depressão apoiada simultaneamente numa agressividade intensa ou em reações de luto (p. 87).

\section{“Ligados" à máquina}

A hemodiálise é o tratamento preferencial dos pacientes renais crônicos, pois estes consideram que ela preserva mais sua autonomia. Os cuidados com a higiene na diálise peritoneal cau- sam-lhes medo, visto que o processo da troca das bolsas que contêm a solução dialítica deve ser recoberto de cuidados para evitar infecções. No entanto, na hemodiálise, a responsabilidade do paciente em seu tratamento é mais restrita, pois ele se entrega aos cuidados da equipe de saúde, ocupando, dessa forma, um lugar de passividade (Almeida, 2003). Contudo, evidencia-se uma ambivalência em relação a esse tratamento. Se por um lado a hemodiálise lhe permite ter uma ilusão de independência da doença durante o tempo entre uma sessão de diálise e outra, por outro lado, no momento em que o paciente está "ligado" à máquina, as limitações da doença e sua dependência do aparelho aparecem com toda a sua intensidade.

"Enquanto nós temos na máquina nós somos escravos. Tem que esperar, nós vamos pagar, esse é um mico que nós vamos pagar toda a vida” (E3, aposentado, pré-transplante).

Alguns pacientes relatam certo estranhamento e "nojo" quando conectados à máquina pela visão de seu sangue saindo e entrando em seu corpo. Rodrigues (1979) afirma que:

A reação de nojo se aproxima da reação do medo, na medida em que ambas se defrontam com o perigo representado pelas coisas anômalas, ambíguas, intersticiais e transgressoras, que ameaçam o controle que o homem exerce sobre o mundo, controle que lhe proporciona toda segurança (p.140).

\section{A perda da identidade}

O desenvolvimento da doença é uma seqüência de perdas que conduz ao esfacelamento do corpo, repleto de cicatrizes geradas pelas fístulas, cateteres, exames e cirurgias. Por mais que se negue a doença, essas marcas estão inseridas no corpo atestando que o sujeito pertence a uma classe específica. As perdas corporais são vivenciadas com privação ao nível do funcionamento orgânico e do prazer corporal requerendo um processo de luto. A função sexual é uma das principais afetadas pela doença, pois esta provoca a perda da libido e da potência sexual (Borges, 1998; Diniz et al., 2002).

"Claro que tu não tem mais aquela atividade que tinha no ato sexual, o cara perde a virili- 
dade, não é mais a mesma pessoa" (E4, aposentado, pré-transplante).

Diniz et al. (2002) assinalam que as modificações que o corpo sofre em decorrência da doença exigem do pacientes um processo de luto, pois equivalem à perda de um objeto de amor.

\section{Suporte emocional}

A fé em um ser superior e na religião, que aparece nas narrativas dos pacientes como fonte de esperança e força, traz conforto e possibilita que a doença e o transplante sejam significados de alguma forma (Borges, 1998).

"A gente orava bastante, né! A gente pedia para Deus qual seria o caminho melhor, né! (...) Assim a gente tendo fé, ajuda até o psicológico da gente" (E7, aposentada, transplantada).

No ambiente intra-hospitalar, os pacientes em hemodiálise constroem vínculos afetivos intensos com a equipe de saúde, uma vez que atribuem seus cuidados não só físicos a esta, mas também os emocionais.

"As gurias da enfermagem tão sempre em cima, sabe! Sempre conversando com nós, trazem revistas, falam sobre tudo. Então, às vezes, não tem como tu ficar triste. Sabe... sentar naquela cadeira, ficar quieta, fechar os olhos e ficar emburrada, como se diz assim... Não tem!" (E2, dona de casa, pré-transplante).

Já entre os próprios pacientes estabelece-se um vínculo identificatório: sensibilizam-se com o sofrimento e conflitos vivenciados pelos seus iguais. E o laço em comum entre eles - a doença renal crônica - identifica-os como uma família.

"Há um entrosamento muito grande entre o pessoal que faz hemodiálise, a gente passa... tudo que a gente convive aquilo ali, três vezes por semana, quatro horas. Então cria... aquilo ali é uma família" (E1, aposentado, transplantado).

A família original também oferece apoio imprescindível ao seu ente enfermo, uma vez que a doença e o tratamento alteram a rotina de todos. Muitas vezes, a família necessita se readaptar à nova realidade da doença, tendo que rever e redistribuir seus papéis dentre aqueles que permanecem sãos, como uma forma de manter a homeostase familiar.

\section{Escolha do doador}

A escolha de um doador, pelo paciente, para transplante, envolve questões afetivas e familiares, além de um processo de seleção clínica e bioquímica. Receber um enxerto vivo, segundo os participantes, é preferencial, pois o organismo tem menos probabilidade de rejeitar um órgão que lhe é compatível biologicamente. Entretanto, esse não é o único critério que delibera esta escolha, é necessário que também haja, de acordo com os entrevistados, uma certa compatibilidade afetiva entre doador e receptor. Com isso, surgem sentimentos ambivalentes no paciente, pois um doador vivo, ao mesmo tempo em que assinala com uma melhor qualidade de vida para ele, também implica em colocar em risco a saúde de um familiar/amigo (Borges, 1998).

\begin{abstract}
"Minha mãe queria doar para mim... Eu ficava com medo de que depois se acontecesse com ela o mesmo que aconteceu comigo, ela tirar o rim para dar para mim e depois ela ficar com problema, né! Depois vir toda por cima de mim, remorso, né!" (E7, aposentada, transplantada).
\end{abstract}

\section{0 transplante renal}

Sair de um tratamento dialítico e optar por um transplante, algumas vezes, é uma escolha angustiante, permeada de medos e dúvidas sobre a eficácia dessa terapêutica e o momento de fazêla. Com isso, muitos pacientes utilizam-se de mecanismos de defesa a fim de diminuir sua ansiedade e idealizam o transplante como uma forma de cura, mostrando-se indiferentes às orientações da equipe de saúde quanto aos cuidados e intercorrências pós-cirúrgicas. Após receberem o rim enxertado, a realidade mostra-se diferente da imaginada. Se por um lado recuperam parte de sua liberdade, não tendo que depender mais de dietas 
alimentares e hídricas tão restritivas, por outro, passam a desenvolver outras dependências, como a dos medicamentos imunossupressores e do acompanhamento ambulatorial contínuo (Borges, 1998).

"O transplante é um tratamento, se está em constante tratamento. Tem que fazer revisões, eu venho aqui de 4 em 4 meses, mas tem que vir fazer os exames (...) A gente está em constante tratamento, toma os remédios, que os remédios tem que tomar para o resto da vida" (E1, aposentado, transplantado).

\section{Considerações Finais}

Os pacientes vivenciam a doença como uma forma de ruptura em suas vidas. A construção da fístula para a realização da hemodiálise e a introdução do cateter para a diálise peritoneal são episódios marcantes, pois delimitam a entrada dos pacientes em um novo mundo: o dos doentes renais crônicos. O inchaço decorrente do acúmulo de líquido e das alterações físicas provocadas pelos medicamentos é também prova dessa inserção. As marcas no corpo são vistas como o atestado que mostra serem, os seus portadores, sujeitos diferentes dos demais.

A religião surge como forma de apoio para enfrentar essas mudanças decorrentes do adoecimento, pois pela crença em um ser divino, tenta-se atribuir significados à doença e ao tratamento. Além da fé depositada em um ente superior, para os pacientes que realizam a hemodiálise, a equipe de enfermagem e os colegas de hemodiálise oferecem suporte afetivo pelo vínculo que se cria entre eles no ambiente intrahospitalar.

A possibilidade de realizar o transplante é idealizada como uma forma de cura e retorno à vida dita 'normal'. É no período após a cirurgia que os pacientes percebem-se responsáveis pelos cuidados com o rim enxertado e a necessidade de realizar um tratamento para 0 restante de suas vidas. Com esta pesquisa, ficou evidente que a escolha do doador envolve tanto aspectos médicos quanto psicológicos e familiares, pois, apesar de considerarem ser mais benéfico receber um rim vivo, os pacientes preferem entrar para a lista de espera por um doador cadáver, a fim de não prejudicar seus familiares e não os colocar em sacrifício.

\section{Referências}

Almeida, A. M. (2003). Revisão: A importância da saúde mental na qualidade de vida e sobrevida do portador de insuficiência renal crônica. Jornal Brasileiro de Nefrologia, 25 (4). Recuperado em 15 de abr. 2004: www.sbn.org.br.

Bardin, L. (1988). Análise de conteúdo. Tradução de Luís Antero Reto e Augusto Pinheiro. Lisboa: Edições Setenta.

Barros, E.; Gonçalves, L.F.; Manfro, R.C. \& Thomé, F.S. (1994) Nefrologia: rotinas, diagnóstico e tratamento. Porto Alegre: Artmed.

Berger, P. L \& Luckmann, T. (1976). A construção social da realidade. Petrópolis: Vozes.

Borges, Z. N. Da doença a dádiva: um estudo antropológico sobre transplantes de órgãos através da análise do transplante renal. Porto Alegre, 1998, 177 f. Tese de Doutorado em Antropologia Social, Universidade Federal do Rio Grande do Sul, Porto Alegre.

CRP-SP. (2003). Progresso na saúde inclui psicologia hospitalar: profissionais conquistam reconhecimento e ajudam na recuperação de pacientes. Jornal de Psicologia CRP-SP, (137).

Diniz, J.S.S.; Filho, J.B.M. \& Lima, A.M.C. (2002). Insuficiência renal crônica - A trajetória de uma prática. In: B.W. Romano (Org.) A prática da psicologia nos hospitais (pp.77 - 92). São Paulo: Pioneira.

Duarte, L. F. D. (1986). Da vida nervosa nas classes trabalhadoras urbanas. Rio de Janeiro: Jorge Zahar/CNPq.

Finkelstein, F.O . \& Finkelstein, S.H.(2000). Depression in chronic dialysis patients: assessment and treatment. Recuperado em 04 abr. 2004: www.jkms.kams.or.kr.

Huh, W.; Kim, A.J.; \& Lee, Y.K. (20020. Analysis of depression in continuous ambulatory peritoneal dialysis patients. Recuperado em 30 mar. 2004: www.ncbi.nlm.nih.gov.

Jovchelovitch, S. (1995). Vivendo a vida com os outros: intersubjetividade, espaço público e representações sociais. In: P. A. Guareschi \& S. Jovchelovitch (Orgs.) Textos em representações sociais (pp. 63 - 85). Petrópolis: Vozes. 
Júnior, C.G. \& Zimmermann, P.R. (2002). Falência e transplante de órgãos. In: N.J. Botega (Org.) Prática psiquiátrica no hospital geral: interconsulta e emergência (pp. 298 - 313). Porto Alegre: Artmed.

Lima, A.F.C. $\mathbf{O}$ significado da hemodiálise para o paciente renal crônico: a busca por uma melhor qualidade de vida. São Paulo, 2000, 131 f. Dissertação de Mestrado em Enfermagem, Escola de Enfermagem de São Paulo, São Paulo.

Loyola, M. A. (1984). Médicos e curandeiros: conflito social e saúde. São Paulo: Difel.

Maciel, S. C. (2002). A importância do atendimento psicológico ao paciente renal crônico em hemodiálise. In: V. A. Angerami-Camon (Org.). Novos rumos na psicologia da saúde (pp. 55 - 85). São Paulo: Pioneira.

Minayo, M.C.S. (Org.) (2002). Pesquisa social: teoria, método e criatividade. Petrópolis: Vozes.

Montero, P. (1985). Da doença à desordem, a magia na Umbanda. Rio de Janeiro: Graal.

Moraes, R. (2003). Uma tempestade de luz: a compreensão possibilitada pela análise textual discursiva. Ciência e Educação, 9 (2), 191-211.
Moscovici, S. (2003). Representações sociais: investigação em psicologia social. Petrópolis: Vozes.

Penna, T.L.M. (1992). Psicoterapia breve em hospitais gerais. In: J. M. Filho (Cols.). Psicossomática hoje. Porto Alegre: Artmed.

Quintana, A.M. (1999). A ciência da benzedura: mau olhado, simpatias e uma pitada de psicanálise. São Paulo: Edusc.

Rodrigues, J.C. (1979). Tabu do corpo. Rio de Janeiro: Achiamé.

Uryn, M.B. (1992). Transplantes renais. In: J.M. Filho (Cols.) Psicossomática hoje (pp.279 - 286). Porto Alegre: Artmed.

Vergoulas, G. (2002). Quality of life in patients with kidney transplantation. Hippokratia, 6 (1). Recuperado em 24 jun. 2004: www.kidneytransplant.com

Recebido em/received in: 31/08/2005 Aprovado em/approved in: 06/12/2005 